Instructions for authors, subscriptions and further details:

http://rasp.hipatiapress.com

\title{
Gender, Widowhood and Female Solidarity: A Study on Female Friendships of Later-life Widows
}

Sayendri Panchadhyayi

Presidency University. India

Date of publication: January $30^{\text {th }}, 2021$

Edition period: January 2021 - July 2021

To cite this article: Panchadhyayi, S. (2021). Gender, Widowhood and Female Solidarity: A Study on Female Friendships of Later-life Widows. Research on Ageing and Social Policy, 9(1), 26-50. http://10.4471/rasp.2020.5053

To link this article: http://dx.doi.org/10.447/rasp.2020.5053

\section{PLEASE SCROLL DOWN FOR ARTICLE}

The terms and conditions of use are related to the Open Journal System and to Creative Commons Attribution License (CCAL). 


\section{Gender, Widowhood and Female Solidarity: A Study on Female Friendships of Later-life Widows}

Sayendri Panchadhyayi

Presidency University.

(Received: 11 January 2020; Accepted: 1 June 2020; Published: 30 January 2021)

\section{Abstract}

Friendship is an intrinsic aspect of living across generations. This study encapsulates female friendships for widows in later-life in negotiating ageing and widowhood. However, the significance of friendship for the silver generation has received limited attention from gerontological studies in India. The study has incorporated qualitative interviewing and oral narratives administered through semi-structured questionnaire conducted in the setting of the respective residence of the respondents. It was found that the social context of ageing and the structural context shape the experiences of friendship. Friendship can be low maintenance for these women; however a friend is one through interaction with whom one derives equanimity contentment and meaning for leading life without the presence of spouse. They challenged the notion of normative understanding of friendship by identifying kin members sometimes across generations as friends. Female friendship is not fragile and they feel that it is more intense and laden with emotions compared to male friendship.

Keywords: ageing, widow, friendship, gender, older women

2021 Hipatia Press

ISSN: 2014-6728

DOI: $10.447 /$ rasp.2020.5053 


\section{Género, Viudedad y Solidaridad Femenina: un Estudio sobre las Amistades Femeninas de las Viudas}

Sayendri Panchadhyayi

Presidency University.

(Recibido: 11 enero 2020; Acceptado: 1 junio 2020; Publicado: 30 enero 2021)

\section{Resumen}

La amistad es un aspecto intrínseco a lo largo de la vida, entre generaciones. Este estudio resume las amistades femeninas de las viudas en la vejez al negociar el envejecimiento y la viudez Sin embargo, la importancia de la amistad para la "silver generation" ha recibido poca atención de los estudios gerontológicos en la India. El presente estudio ha incorporado entrevistas cualitativas y narrativas orales desarrolladas a partir de un cuestionario semiestructurado realizado en el ámbito de las residencias de los propios encuestados. Se encontró que el contexto social del envejecimiento y el contexto estructural dan forma a las experiencias de amistad. La amistad puede estar poco mantenida para estas mujeres; sin embargo, un amigo es aquel que a través de la interacción se obtiene ecuanimidad, satisfacción y significado para llevar la vida sin la presencia de su cónyuge. Estas mujeres desafiaron la noción de comprensión normativa de la amistad al identificar a los parientes a veces a través de generaciones como amigos. La amistad femenina no es frágil y sienten que es más intensa y cargada de emociones en comparación con la amistad masculina.

Palabras clave: envejecido; viuda; amistad; género; mujeres de edad avanzada

2021 Hipatia Press

ISSN: 2014-6728

DOI: $10.447 /$ rasp. 2020.5053 
$\neg$ he waning of relationships, increasing loneliness and deterioration of health marks the old age. However, men and women experience widowhood differently (Streib, 1970; Davidson, 2004). The prevalence of proscription regarding malefemale interaction along with the culture of seclusion of women to the private realms lead to a situation of homosocial interaction especially in the Indian sub-continent. As argued by Bird (1996), the term homosocial suggests sociability with the same sex member. Such homosocial interactions among women provide space for releasing intergenerational vexation, negotiation with the decaying body and exchange of advice on leading a meaningful life. Within the rubric of friendship, the gendered dimensions of friendship and connotations of neighbourhood networks for aged widowed women has been a less explored theme in the context of gerontological literature emerging from India. An aged widow anguished by the pain from the loss of her husband and her waning power within the family seeks to establish relationship with women (Stevens, 2001). As noted by Blau (1961, p. 431) and Davidson (2004) widowhood seems to have no adverse effect on social participation, as widowhood is common among the aged women. Regular interaction with the members of the personal network has positive effect on the widows making them feel more socially integrated and decreasing their sense of loneliness (Mannell, Dupuis, \& Birren, 1996; Stevens, 2001). The present metamorphosis and the range of diversity during old age can be understood through three dimensions(1) The changes in roles and transitions in later life, (2) the changes in expected returns from the relationships within the network, and (3) individual proactive management of personal relationships. According to Jerrome (1981, p. 178), studies on friendship on older people are oriented towards the structural aspects of the dyadic pair rather than the quality of friendship. Gerontologists and community sociologists have emphasized on examining the position of specific dyads in case of individual networks (Jerrome 2008, p. 178-179). They are of the view that an understanding of the quality of friendship among the elderly population like the significance of friendship in the face of distance, 
widowhood, illness or death (Adams, 1987, p. 222), the nature of commitment to friends and the changing meaning of friendship across the life course would make these studies more rigorous and incisive. It is important to note that friendship is intricately tied to time. An individual requires time to make and nurture friendship. This is because retaining friends demand keeping in touch with the friends, enquiring about their health and devoting time that may interfere with the maintenance of relationship with the kin group. Adams's (1985) work on friendship have focused on the role of social space and physical distance in establishing emotional closeness. Studies on friendship are largely associated with children, adolescent and the adult, thereby indicating a negative correlation between ageing and friendship. In simple words it translates to the view that as one grows old, the number of friends become low or limited. Through documentation of oral narratives, this paper seeks to explore the changes and continuity in the continuum of friendship from their marital status to widowhood, whether the loss of spouse strengthens the tie of friendship and whether consolidation of friendship is an indicator of lack of intimate bonding with the present family members. I further intend to identify the ways in which widowed women identify friends and friendship through the life course.

\section{Methodology}

Selection of the respondents was made through non-probability purposive sampling. The number of respondents who participated in this study are 7 . Personal visit to the home setting of the participants were made once, however in case of clarifications with the collected information, telephonic conversations were made later. Data was elicited over the months of August and September, 2019 through personal face-to-face, intensive qualitative interviewing, and oral narratives administered through a semi-structured questionnaire with several open-ended questions. The semi-structure nature of the questionnaire allowed for questions to be added, eliminated or modified depending on the circumstances and rapport developed with the participants. Along with this observational notes were made. Considering the elderly 
widows were identified and approached through my peer network, this sampling technique was deemed suitable. In few of the cases, I personally went to the participant after a mutually known person communicated about the purpose of my research. However, in certain situations, a mutually known person was present during the interview and that facilitated the interview by communicating some of the questions to the participants. I also made on-site observation or observation of the ecological setting of the respondents.

Another method that was incorporated for the study was collection of household stories from colleagues, peer groups and friends regarding their perspectives on the significance of friendship of their elderly widowed mother-in-law or widowed grandmother. The idea was to stoke their memory about their aged significant others. This method of intergenerational view on widowed friendship paved the recess for unfolding the meanings of friendship and, construction of grey widowed friendship and aged bodies. At the outset of the study the respondents were informed regarding the purpose of the research and were told that in case they felt uncomfortable answering any of the questions, they may refute to respond.

One of the major challenges that emerged during the sampling stage was finding the suitable respondents. Most of the widowed women who could have been approached were leading a withdrawn life, preferring to limit themselves to the private sphere, snapping their ties from the bustle of the 'public sphere' and dedicated themselves to a spiritual life. In few instances potential respondents rejected to being interviewed without citing any proper reason. In addition to health issues, this may be attributed to the psychological distress of socializing with people of the same age group with their spouse for company is what makes the widows become this reclusive and opts for a cloistered living. Such observation is in contrast with the Blau's (1961) and Davidson's (2004) studies that argue that widowhood does not impinge upon social participation of women. Although this added to the challenge of sampling, nonetheless it made me ruminate upon such behavioural pattern manifested by the widowed women. Another challenge that the study had to grapple with is the presence of family members who would keep surveillance, interpret the questions on my behalf and often answer for the respondents. Therefore, during the interpretation of the interview transcripts and the thematic arrangement of the data I was careful to illuminate on the source of the oral narratives. 


\section{Panchadhyayi- Gender, Windowhood and Female Solidarity}

\section{Profiling the Respondents}

The participants in this study were between the age group of 60 and 87 . They are residents of Southern part of Kolkata, Bengali by ethnicity and belong to middle and upper-middle-class households. As observed by Bagchi (1993, p. 2214), patrilineal patrilocal family structure has been the norm of caste Hindu Bengal. Therefore, all the respondents post-marriage located to their husband's family ${ }^{1}$. An interesting facet about the participants of this study is that majority of them were partition survivors or migrated to independent India during 1972 Bangladesh war of liberation. Their narratives on friendship were interspersed with the trauma of partition ${ }^{2}$, the convolutions of settling in a different country and never feeling fully integrated, a wistfulness to restore the jigsaw puzzle of disintegrated relationships that have been swept across by geo-political currents, generational contrast and gendered experiences. All the participants unanimously declared that they have a placid nature and prefer to stay away from conflictual situations.

Table 1.

Details of the respondents

\section{Name}

Age Family members present at the time of interview aiding to the memory of the respondents and supplementing the narratives

Shiuli (lives in a multi-generational household 81 Daughter and granddaughter with daughter, son-in-law and granddaughter)

Mala (sister-in-law of Shiuli lives in a 68 Granddaughter multigenerational household with her son, daughter-in-law and granddaughter)

\begin{tabular}{|c|c|}
\hline $\begin{array}{l}\begin{array}{l}\text { Shoma (lives with middle and younger } 63 \\
\text { daughter) }\end{array} \\
\end{array}$ & Two daughters \\
\hline $\begin{array}{l}\text { Tapati (lives in a multigenerational household } 87 \\
\text { with her son, daughter-in-law and grandson) }\end{array}$ & $\begin{array}{l}\text { Shoma and her younger was present } \\
\text { (her younger daughter introduced to } \\
\text { Tapati) }\end{array}$ \\
\hline Anjana (lives alone) & No one was present \\
\hline $\begin{array}{l}\text { Nalini (lives in a multi-generational household } 65 \\
\text { with her sister-in-law, their sons and daughters- } \\
\text { in-law, and their children) }\end{array}$ & No one was present \\
\hline Kakoli (lives alone) & $\begin{array}{l}\text { Her daughter and my peer who } \\
\text { introduced to Kakoli }\end{array}$ \\
\hline
\end{tabular}




\section{Findings and Discussion}

In the study, neighbourhood friendship or neighbourhood network played a key role in determining the intensity of friendship. Intensity of friendship is contingent on the geographical location of two friends as it facilitates easy mobility in times of distress, seeking suggestions through face-to-face mode and sharing food with each other that has surfaced in the narratives of all the respondents. According to Beeson (1975, p. 54), gerontological literature constructs the plight of widowhood with that of the plight of men retiring from their professions. As suggested by Streib (1970, p. 262), women demonstrate better abilities compared to men in establishing quasi-relationships and coping with the loss of their husband by engaging in domestic skills as that constitutes a considerable volume of their life. However, the empirical data challenges this theoretical edifice considering that the elderly widows part of this study have limited their social interaction and sociality after the demise of their husbands. Some of the participants appeared diffident at the allusion of interaction with men as friendship. Two of the respondents who have been engaged with out-of-home paid employment referred to few female colleagues as 'friends', however for them the male colleagues were only 'colleagues' although there is a sense of cordiality. This may be surmised as the cultural notion of modesty of the time, space and generation where intersex friendship was deemed as taboo and impinge on the honour of both the sexes. According to Adams (1985, p. 610), elderly women perceived crosssex friendships with age peers is associated with having romance that may be owed to the proscriptive norms. Therefore, elderly women do not define friendship with men in the same way, the way they would define friendship with the same sex.

The study did not impose any pre-conceived notion of friendship on the respondents rather provided the space to the respondents to articulate the meanings and attributes, they associate with friendship. Based on the questions asked to the respondents and the information collated, six major themes have been identified. The study has made an attempt to understand the notion of intimacy and emotional connectedness experienced in friendship through the themes of the exclusivity of female friendship and whether it is different from male same-sex friendship. The next theme is on gift exchange and the ways in which it fosters and facilitates friendship for these elderly 


\section{Panchadhyayi- Gender, Windowhood and Female Solidarity}

widows. The following theme is woven around how the distinction between friends and intimate others (family members) is made and whether such differentiation is feasible. The fourth section deals with the divergent views regarding friendship that existed during the respondents' generation and friendship in this era. The fifth section revolves around the role of friends in tending to one's illness or alleviation of illness. The last theme centres on the dynamics of friendship in case of one-to-one friendship relations and group friendships.

\section{Memory and Friendship: Busting the Negative Stereotyping of Female Friendship}

Mala, aged 68 who lives in an intergenerational family and has devoted herself to spirituality quipped that female out-of-home employment competes with friendship. This may allude to the attribute of friendship demanding 'time', 'nurturance' and 'mutual understanding' to grow (Allan, 2008). Romanticizing about the past and disenchantment with the contemporary rubric of friendship were found to shape their views about friendship. Female friendship is traditionally believed to be coloured with jealousy, betrayal, clash and rivalry. It is juxtaposed to the sphere of male friendship that is associated with 'brotherhood' or fraternity (or the bro-code), durability and standing the test of time, and mutual harmony or complementarity. This gendered imagining of friendship makes female friendship or feminine solidarity a myth. However, the data generated from the field confronts to the layered meanings of female friendship for aged widows, the intricacies of emotions that accompany the reminiscence of a friend and the beckon of hope that represents female solidarity. For a widowed woman friendship allows the scope for coping with the multiple life conditions of being a woman, struggling with generational contrast with the vertical generations, bereavement of the husband and subsequent trials and tribulations, coping with the trauma of widowhood, coming to terms with the aged body and rising above the plight of chronic illness.

The views of two of the respondents become important to illuminate on this further. Shiuli aged 81, lives with her daughter, son-in-law and granddaughter. She lost her husband to cardiac arrest. She recollected that the intensity of her bonding with her best friend went beyond time and space. 
Shoma, aged 63, believes that "meyeder sate meyeder bondhuttyo sarajibon er" (friendship between and among women lasts lifetime). These insinuate the essence of female solidarity and friendship for older women especially widowed women for whom friends become a conduit to counter stigma, loneliness and helplessness (Stevens, 2001). She has helped her friends financially however she was quick to withdraw when she realized that someone is making it a habit to approach her frequently by taking unfair advantage of her. She strongly feels that money can create rift between friends, therefore she declined the request of her friend and sent her back predicting the hedonistic and materialistic nature of money that can ruin friendship. She shared that she reconnected with her school friend from Bangladesh, post-1947 partition in Kolkata. She was separated from many of her friends due to partition. It may be surmised that partition not just demarcated geographical spaces, religious affiliations and families but it also separated friends. However, her narrative is replete with hope- She reunited with her friend in the independent India and since then has shared a bond spanning across 40-42 years. She believes that ideological difference is not an obstacle in the path of friendship, provided that both can share their personal thoughts with each other.

Tapati, aged 87, recounted that after the loss of her husband, her neighbourhood friend became a solace to her distress. Earlier she was a resident of Shovabazaar ${ }^{3}$ in North Kolkata where she befriended with an elderly woman. She is not aware of her name arguing that "agekar din-e boroder naam jigesh kora hoto na" (It was considered taboo to ask the elders their name), unlike today's generation that audaciously asks the name of an elderly person! On her views regarding who can be deemed as a friend, she noted that a friend is one with whom one can share the innermost feelings"Jar sate mon-er kotha bola jae, jar sate kotha bole shanty paowa jae, ekek jon er sate kotha bole valo lage" (a friend is someone with whom I can share my feelings, with whom I can find peace on talking and there are certain people on talking with them one derives a sense of contentment!).

Anjana was a stenographer who completed her college in private and migrated from Assam to West Bengal for higher education and job opportunities. She joined her service with the Income Tax Department in 1968 and is currently 71 years. On friendship, she told me that her friend circle comprised of her female colleagues from her workplace with whom she has 


\section{Panchadhyayi- Gender, Windowhood and Female Solidarity}

maintained her friendship. She was unequivocal in expressing that she never had any male colleague as friend indicating the taboo on cross-sex friendship that constituted the moral compass of a particular generation (Adams, 1985). She has travelled with her group of friends to different places across the country where the travel and tourism company arranged the travel itinerary. She lost her husband on 2016 and since then has limited sociality. She has a penchant for gardening and talks to plants. She feels that the plants that she does not take much care properly meet with their decay and eventual death, as they feel neglected. She also loves animals and shares a deep sense of attachment with them. Her life story surpasses friendship beyond human beings, she is of the opinion that the friendship that she shares with plants, and animals is more special as they reciprocate and show gratitude. She does not like interacting much with the neighbourhood network (para-r lok ${ }^{4}$ ) as women of her generation is primarily interested in spiteful allegations and shallow gossip regarding their respective daughters-in-law. She feels that there should be no distinction made between the daughter and the daughter-in-law. The latter should be provided with adequate time to adjust with the family and the mother-in-law needs to be more far-sighted in dealing with the complex situations that may emerge in the sansaar. A strong element of friendship is required in the mother-in-law and daughter-in-law relationship to survive the test of time. The friendship does not exist organically but one has to nurture it like a plant. She knows the usage of WhatsApp but feels that the sense of comfort that she feels during a verbal communication over phone is unparalleled to any virtual communication. Communication through social media promotes distance in friendship. During times of distress, providing instrumental and mental support to either office colleagues or neighbourhood networks is a marker of friendship manifestation. She has felt neglected in situations where there is a strong dyad or triad bonding in a large group of friends. However, at old age it is difficult to be that strong-headed and completely distance with certain friends. Therefore, friendship in the old age is defined by more restraint. She believes that the nature of friendship should be such believe that even if one cannot devote much time, whenever they communicate the spark would remain the same. She meets with friends although the contact of frequency has reduced. She praised 'Barishtho Nagorik $^{5}$ club' in Dumdum where there are multiple recreational activities for the elderly and a step towards grey solidarity and inclusion. She laments 
saying that such an initiative is absent in her para. Friendship clubs may become helpful for the elderly people for establishing ties with others based on mutual interests, however the success of clubs may be limited as loneliness cannot be a sole driving force for fostering friendship (Stevens 2001, p. 186). She challenged the negative stereotype of female friendship and asserted that 'meye ra meye-der khub bhalo bondhu hote pare' (women can become each other's best friend) given they have learnt the right values of treating another woman with respect, cordiality and empathy from a female role model in home. To substantiate her statement she shared about the camaraderie that defines her relationship with the mother of her friend. This is an interesting view that may indicate that being a good friend is defined by certain characteristics and, those characteristics are internalised and learnt during the course of adolescent socialisation by observing and interacting with a female member in the family. Her statement further illuminates on the role of family in this case a female family member in shaping the characteristics of an individual that would reflect in her attitude to friends and friendship.

Nalini is a resident of Deshapriya Park ${ }^{6}$ who shares the household with her sister-in-law (husband's brother's wife) and their children and grandchildren in a three-generation family system. However, she stays on the ground floor, cooks her daily food believes in spatial boundaries. She is the only respondent in the study who had love marriage in 1974 and who is a native of West Bengal. While sharing about her love story set in the 1970s Bengal, she was punctilious to highlight the submissive and timid role played by her in the blossoming of the relationship to marriage and it was only the active action of her late husband that formalized the relationship. She also clicked her tongue when she accidentally pronounced the name of her husband that was forbidden for married women. Unlike the rest of the participants, her life story had no connection to the 1947 partition. Regarding friendship, she said that it was the advice of her best friend that bolstered her to accept the marriage proposal of her late husband. Her friend guided her by saying that he is a suitable match and it would be naive of her to reject that proposal. Post her marriage she had to disconnect with friends from college as the domestic responsibilities kept her occupied. She accepted that for women it becomes difficult to maintain the friendship after marriage considering that the world of her husband plays a more crucial role. This view is consistent with the finding of Blau's (1961) study on friendship where she argues that filial 


\section{Panchadhyayi- Gender, Windowhood and Female Solidarity}

responsibilities often takes over maintaining friendship as it demands time and energy. It may be argued that the anticipatory socialization that a woman undergoes after her marriage changes her priorities in life. She is expected to perform her domestic chores and weave the family together ensuring that she does not become the source of tension or discontentment for the family members. Given the consolidation of friendship demands time for nurturance, married women often have to forgo the school and college friendships. According to Adams (1987) and Allan (2008, p. 5) as individuals move through the life course, the sets of relationship they form may change. Their new friend circle becomes the wives of their husband's friends much like the transition from the natal home (baaper-bari) to the husband's home (shoshurbari). Therefore, marriage for the elderly widows in this study not just brings about a transformation in family relationships but also friendship. Such transitions may be attributed to the married woman's desire to obey the husband's orders. Seeking the husband's decision regarding friendship to maintain marital harmony has also surfaced in this study. She recounted her experience of transitioning from a girl of a middle-class, Brahmin, conservative family to the daughter-in-law of a 'bonedi ${ }^{\text {'7 }}$ family settled in the upscale enclave of South Kolkata family. However, she could not adjust to the lifestyle of her husband's friends and felt alienated. She felt that her middleclass, conservative upbringing clashed with the elite 'club culture'. Her husband's friends used to go to clubs like International Club and Outram $\mathrm{Club}^{8}$ where consuming alcohol was part of etiquette. She was always repulsed towards the idea of consuming alcohol. There used to be home gatherings with her newly formed alliances with her husband's friends' wives. However, after the death of husband she chose to stay away from sociality and devoted herself to a spiritual life. Another reason for her to distance herself from the gatherings is the tendency of her cohorts to consume alcohol that has always made uncomfortable. There have been circumstances where she has helped her college friends to meet with their respective boyfriends.

Kakoli, an 86-year old woman who has been an active woman throughout her life and continues to remain absorbed in nurturing her creative skills. During her youth, she has been to different cities in India along with a tour group without her husband accompanying her. According to her and her daughter, her husband has been supportive of her autonomy and respected her agency. According to her, her jovial nature and friendly demeanour have made 
her acceptable for different people. Her para folks visit her and enquire about her health. On the contrary, her daughter who is also an elderly widow never had a strong friend circle, as she preferred to be on her own. However, she had friends who would enquire from her about her whereabouts and post the demise of her husband called her up and offered their sympathy.

\section{Food, Saris and Gifts: Exchange and Reciprocity}

Sharing food is associated with intimacy and consolidation of bond (Miller, Rosin, \& Fiske, 1998). Shiuli recollected one incident from her childhood where her group of friends (5) bought three samosas (a fried savoury item stuffed with potatoes cooked in spices, quite popular in India) and shared those among each other as the other two girls in the group could not afford for the samosas. This is evocative of the significance of sharing food as an important attribute of proximity. Another activity that was found to be strengthening friendship and elevates it to fictive kinship is cooking a dish and giving it to the other friend. Thirdly, potluck where each of the friends cooks and shares it together is another attribute of friendship and food sharing. Apart from the domain of food, borrowing sari ${ }^{9}$ from a friend for occasions or marriage suggests the depth of friendship. However, they lamented that contemporary friendship lacks such intimacy thereby indicating a transformation in intimacy in present day larger web of relationships.

Shoma stated that she fears loneliness and hence, finds it difficult to stay alone. She needs someone to provide company to her. The suffocation of loneliness grew adverse with the loss of her husband. She also lost her first child. However, these human losses have not imbued bitterness in her. On the contrary, it has taught her to be compassionate and giving. Her two younger daughters run a bakery business that keeps them occupied and out of home for prolonged period. They are also into trekking that means they have to stay out of home for days. During the absence of her daughters, she visits her friend in the neighbourhood, go for sari shopping in the Jadavpur area or shopping for meat. She is dependent on her friends for companionship. However, at night when she goes to sleep, the pang of loneliness creeps in and makes her yearn for company. The facet of shopping and friendship as a time for bonding has received limited attention in the existing literature on aged female friendship. Shopping involves sharing opinions, awareness about each other's tastes, and 


\section{Panchadhyayi- Gender, Windowhood and Female Solidarity}

disapprovals over choices that renders insight into the recesses of one's aesthetics and derive a sense of empowerment, and autonomy in making decisions over what to buy, and feeling validated when those choices receive approval from the friends.

Shoma was of the opinion that that due to her limited access for vacation, she hardly gets any opportunity to bring gifts for her friends. However, her friends get her gifts whenever they go for a trip. She was quick to notify that she compensates for the gifts bestowed by her friends by offering them her handcrafted food. All these acts of exchange indicate that gifts may not be the yardstick of determining friendship, however it does facilitates and consolidates friendship.

\section{Friends like Family, Family like Friends}

An important aspect of this study was the frequent blurring lines between the boundaries of family and friendship that has earlier been dealt by Pahl and Pevalin (2005). The notion of who is to be considered as friend and who is to be considered as family often was at cross-section. This brings to the illustration of Mala who stated that her jaa or sister-in-law (husband's brother's wife) was her best friend, however after her death no one could fill her vacuum. The feelings that stoked such emotion for her sister-in-law can be understood through the concept of 'families of choice' that emphasizes on kin-like networks embedded in commitment and friendship beyond the paradigm of blood relationships as argued by Pahl and Pevalin (2005, p. 433434). In instances of differences with her friends, she shares her disappointment with her daughters rather than going through an actual confrontation.

According to Bengtson (2001), multigenerational bonds are becoming relevant in the climate of increase in divorce, shift in traditional patterns of family, rise of binuclear families and to fulfil for the deficit of childcare when both the parents are engaged in out-of-home employment. However, in the light of India, the traditional family system comprising of multiple generations sharing the same household promotes an intense intergenerational exchange and has been present for a long period. Therefore, intensification in multigenerational bond is not a new phenomenon for India but it may be argued that the changing patterns of family in the urban space is leading to 
crevices or making these intergenerational bonds fragile (Lamb, 2009). In the context of my study, the interviews became a site for intergenerational bonding: the granddaughter of Shiuli supplementing the narratives of her grandmother. This indicated that the granddaughter is aware about the personal network, neighbourhood ties and friend circle of the grandmother and this proximity between the alternate generations indicates the cordial nature of the relationship. The granddaughter administers medicine to my respondent and is aware about the intricacies of her illness. Shiuli who lives with her daughter, son-in-law and granddaughter and the support from the multiple generations does not leave space for activities or responsibilities that otherwise would have been undertaken by the personal networks. It would be interesting to conduct interview with someone who lives alone without any intergenerational assistance and therefore assess the implications of friendship for those widows. One of my respondents became widow during her midthirties and therefore, the impact of widowhood and the associated stigma compelled her to move to another place. On the other hand, the rest of my respondents entered widowhood after their sixties that is considered to the marker of old age and widowhood in such period is although unfortunate but not unexpected. As argued by Victor (2005), a recent shift in the context of widowhood is that it is being experienced in the later phases. She further observes that in the later phase widowhood becomes the norm in the lives of aged women and hence may turn out to be less 'socially disruptive.

"The personal networks of older people reflect their social opportunities and personal choices to maintain a specific set of relationships with relatives, neighbours, friends, acquaintances and so on. "Network analysis is the method used to identify and examine the structural and functional features of the network of the older adult" (Mannell, Dupuis, \& Birren, 1996, p. 243).

Friendship of the elderly widows may be role-based, affect based or contactbased networks. The role-based networks refer to the network maintained by an elderly person based on formal role relationships that would provide them immunity from loneliness, social isolation and illness. The term affect-based network refers to usually the significant others comprising kins and the longstanding relationships. In case of the domain contact network it suggests a large network including the various kin groups, school and job acquaintances, members of organizations, and the neighbours (Mannell, Dupuis, \& Birren, 


\section{Panchadhyayi- Gender, Windowhood and Female Solidarity}

1996, p. 245-247) The study has found that all the respondents are dependent on their domain contact and their notion of friendship encompasses their domain contact. Much like the findings of Pahl and Pevalin (2005, p. 445), the elderly widows in this study identified one or other of their relatives as their friend.

\section{Friendship Now and Then}

Shiuli and Mala emphasized on the 'flat culture' and 'para-r culture' ${ }^{10}$. The para or the bounded locality is imagined as a space of unadulterated bonding and nurturance of intimacy like a close-knit family. The respondents construct 'para' or neighbourhood networks as universally caring, responsive, empathic and prompt. This is contrasted to the flats as breeding a culture of detachment, disinterest in the person staying next to them and being self-consumed. From this account, it may be suggested that a transformation in the geographical space vis-a-vis urbanization and the burgeoning of gated communities, there is a shift in the patterns of everyday relationships including friendship (Bauman, 2003; Allan, 2008, p. 2). Friendship represents/epitomizes warmth, attachment, intimacy like that of a kin and companionship. This echoes Bauman's argument regarding the gated communities functioning with the idea of fortress mentality. According to Jerrome (2001, p. 57), friends who extend relentless support are referred to as quasi-kins, true friend and like a sister, thereby blurring the line separating the friend from the family. All these cannot be pursued or translated in a flat culture where the notion of personal space and commitment to one's intimate others (immediate family) as against friendship outside informs one's worldview. The respondents also believed that that contemporary friendship is selfish, as one would only become a friend for procuring something. It is intriguing to understand that how and why this becomes stigmatized or becomes a taboo given the condition that friendship demands reciprocity, transaction and exchange. The respondents are acerbic about the contemporary friendship being instrumental rather than affective. Friendship over the years is witnessing decay in that strong and intimate bond where one friend can rely on the other. Kakoli cites one illustration that earlier a friend could tell another friend to purchase something for them when the other one is purchasing something, however such frankness may not be possible owing to the infiltration of contemporary values in friendship. 
Shoma was of the opinion that it was her elder sister-in-law (jaa) with whom she felt connected and shared a great rapport. Her death created a vacuum in her life as she lost a parental figure, a wall to recline. She feels that there are certain aspects of life that one should not share with their friends. In her verbatim 'sob kotha sobai ke bola jae na, se jotoi bondhu hok'. This underscores on the friends being close to one's life and yet not fully being a family member as that entails opening up about family secrets and being embarrassed. There are certainly exists boundaries that separates the nature of intimacy pertaining to these two continuums. Her views insinuated at genealogically framed kinship are more reliable than the "families of choice" (Allan, 2008). Allan (2008), family members who are imagined and interacted as friend share a personal bond that is not a "general merging of family relationships into friendship, but a mode of discourse and practise that recognizes the special commitment and trust that exists between the two individuals who happen to be genealogically connected. The facet of embarrassment needs further exploration- whether there is a sense of embarrassment and hence a filtering mechanism organically seeps into conversations with friends.

\section{Friendship and Illness}

According to Kalyan Bagchi (1996), throughout the world, the number of older women outnumber older male therefore making them more vulnerable to old age specific illness and carving a space for their care. He further observes that old age for women is characterized by mainly two broad categories of illness- firstly gynaecological concerns accumulated during the reproductive phase along with the post-menopausal complexities and secondly, the clinical disorders associated with ageing namely hypertension, diabetes, osteoporosis and cardio-vascular issues. The respondents unanimously stated that their friends show concern during the period of illness, provide suggestion on the diet specific to illness, recommend doctors and wellness tips, and there is also a vibrant discussion on the medicine being administered for different illness. Sharing illness narratives with a friend and deriving a sense of catharsis on the ageing body, ailing health and coming to terms with the generational shifts and turns is common among the elderly 


\section{Panchadhyayi- Gender, Windowhood and Female Solidarity}

widows. Although the seniors took pride in talking about their friendship, however on being asked whether their friends bring them medicine or accompany them to the physicians, there was resistance towards the idea. In the Indian social milieu it is the duty of either affinal (kinship established through marriage) or consanguinal kins (kinship established through blood, also known as blood relatives) to provide seva ${ }^{11}$ to the elderly parents (Lamb, 2000, 2009). In this context, administering medicine to elderly family members or taking them to doctors is the rightful duty of the alternate generation (sons and daughter-in-law, and daughter) and the intervention of friends in such matters would denote that the children are not performing their duty, therefore making it embarrassing for the elderly to accept such a situation. It further indicates on fractured parenting and the inability of the elderly women to raise their children with the appropriate values. Considering that the woman is expected to perform the primary role in socializing the children to act in accordance with the societal norms, revelation about children being passive towards the concerns of ailing parents is evocative of 'failure as a parent' and low self-esteem among the peers.

Victor (2005, p. 225) has found that widowhood may lead to high rate morbidity, mortality and impinge on the state of health. Strong ties with friends in the old age has a positive impact on the psychological well-being of the elderly (Blieszner, Ogletree, \& Adams, 2019). Jerrome (1990) discussed the contribution of friends in the alleviation of illness. Knowledge about the illness of one's friend is related to having knowledge about the body of the person, intricacies of the illness and details that may be deemed as vulnerable and embarrassing for the friend. However, sharing certain personal details with a friend amounts to exposing oneself and making oneself vulnerable for further scrutiny. This accessibility accorded to the friend involves leap of faith, a sense of trust and an expectation of reciprocity. However, bereavement may also lead to strain in friendship as one friend may choose isolation from the others to cope with the loss.

\section{Dyadic Friendship and Group Friendship}

Tapati is of the view that dyadic friendship is more intimate whereas the intervention of a third person may harbour jealousy and spike tension"Dujoner modhhye je bondhutyo ta hoe, teen joner modhhye ki $r$ seta hoe 
didibhai!" (The intensity of friendship that takes place between two people cannot happen when three people are friends!). This indicates Simmel's notion of the dynamics of relationship pattern in the dyad and triad. In dyadic friendship, one person can depend on only the other no one else. This nature of interdependency strengthens the quality of friendship (Ritzer and Stepnisky, 2017). However, friendship of group lacks such intensity according to the respondents as it changes dilutes that one to one bond and may complicate the quality of friendship.

According to Mullins and Dugan (1990, p. 382), the frequency of contacts is directly proportional to the sense of loneliness among the elderly people. In addition to it, emotional connectedness has further bearing in the quality of relationship and in the mitigation of loneliness. Friendship heralds a beckon of hope against the pall of loneliness. Therefore, frequency of contact combined with emotional connectedness with friends can reduce loneliness and subsequent depression among the silver generation. For the senior widows in the study brimming with enthusiasm, optimism and zeal towards the nuances of life, friendship become an act of resistance against the prevalent notion of ageism. Female solidarity becomes a way of coping with the stigma of widowhood and not becoming irrelevant. The perpetual struggle is against becoming an anachronism in modern times. In other words, the fear of losing one's relevance among the present generation and becoming obsolete is mitigated by the assurance of network of personal relationships, among which friendship plays a pivotal role.

\section{Conclusion}

Friendship of the later-life widowed women is shaped by the social context of ageing, the collective imaginings regarding female friendships and female roles and, the time and family traditions in which they grew up. It may be rolebased, affect based or contact-based networks. Major transitions like demise of the friend or minor transitions that include out-migration due to marriage, embracing new alliances or friendships along with the family of her husband or partition has implications on the life course of friendship. There is a disdain towards friendships of modernity as these are deemed as impure, lacking intimacy and governed by conspicuous consumerism and juxtaposed with friendships of the past that is pristine, innocent and there embodied purity. In 


\section{Panchadhyayi- Gender, Windowhood and Female Solidarity}

the absence of their husbands, the worldly advice of their friends regarding life and survival has enabled these women to cope with the loss and not succumb to the crevice of depression. However, the respondents for the study were chosen keeping in mind they reside with their family in a household system to ascertain the scope of friendship in a situation of available support. The meaning of friendship for the elderly widows interviewed challenges multiple features concomitant to friendship. Firstly, the notion that female friendship is fragile and cannot survive the test of time. Although pre-marital friendships faces dent as the woman undergoes marriage and shifts to a new geographical location or with mobility, yet there have been instances where old ties have rekindled through common connections. Interestingly, the prolonged period of lull could not impinge the quality of friendship respondents thereby denoting that low-maintenance friendships have been a common feature in the lives of some of the participants. Secondly, friendship is not restricted to the immediate age group but friendships may be established with the neighbourhood network, consanguineal kins and intergenerational kins.

The study indicates that the notion of female autonomy, mobility and the idea of marriage embedded in the society shapes the life course of friendship in the lives of these women. Some of the elderly widows are still coming to terms with the changes ushered in by consumerist modernity and cosmopolitanism, and feel that much like the older ties within the family, friendships today is fragile and high-maintenance. Friendship is marked with a certain level of frankness and reciprocity. Although, the friends do not have to accompany them for physician visits or purchase medicines on their behalf yet they provide lie advice of coping with loss, adversity and transformations of modernity. The latter require emotional labour that is not much recognized by these elderly widows probably because they already have the immediate support of their kins who reside either in the same household or in close proximity. In such circumstances, the emotional labour provided by friends often goes less recognized. Mixed group friendship or inter-sex friendship was a taboo for the participants and they were almost scandalized with the thought of having inter-sex friends. Another significant observation is that none of the respondents expressed dissatisfaction about care reciprocity from their adjacent and alternate generation. Lastly, one of the respondents noted that people who do not have adequate family support or are living alone, seek 
support outside in the form of friends. Otherwise the sansaar ${ }^{12}$ involving domestic duties thwarted them to 'spend time' on friendship implying that the responsibilities of the 'home/domestic' is more important for a woman compared nurturing friendship that is 'outside' the purview of the domestic and demands time.

\section{Notes}

${ }^{1}$ Patrilocal family systems continue to be the norm in many parts of the country. However, with the structural and social change in the Indian families, nuclear family system is becoming common in urban India. See Patricia Uberoi's ‘Family, Kinship and Marriage in India' (1994). ${ }^{2}$ The 1947 Partition was displacement of Hindus residing in undivided Pakistan to India and the displacement of Muslims residing in undivided India to Pakistan. It was exemplified by loss of lives, structural and symbolic violence; gender based sexual crimes and destruction of property. See Sadat Hasan Manto, Urvashi Butalia and Khuswant Singh for further reading.

${ }^{3}$ Shovabazaar is a place in Northern part of Kolkata, West Bengal situated in India.

4 The term 'para' refers to neighbourhood defined by strong interconnection and a sense of community feeling among the residents inhabiting in that area. The notion of para culture alludes to loyalties, a sense of ownership and space of cross-generational prescriptions and proscriptions for the residents. See https://rashidfaridi.com/2014/04/29/wanining-para-cultureof-kolkata-calcuttaindia/ for further information.

${ }^{5}$ The term Barishto Nagorik club refers to informal organizations for the recreation of elderly citizens.

${ }^{6}$ Deshapriya Park is a place located in the southern part of Kolkata, West Bengal situated in India.

${ }^{7}$ The term 'bonedi' refers to the aristocratic joint family culture of Bengal. See Nabamita Das's thesis titled Processes of Negotiating Intimate Heterosexual Identities and Relations' https://core.ac.uk/download/pdf/18614365.pdf

${ }^{8}$ International Club and Outram Club are two reputed clubs situated in Kolkata, India. Entry and access to clubs denote one's membership into a higher status and elite class in the society. ${ }^{9}$ The term sari derives from the word 'sattika' which was originally three-piece ensemble. The mention of this ensemble can be found in Buddhist Pali literature of 6th BCE and Sanskrit literature. Sari is a traditionally costume traditionally donned with blouse that covers the upper part of the body and petticoat that is worn in the lower half of the body, underneath the sari, on the blouse and the petticoat, the sari is then draped. Sari is a popular traditional attire in many parts of India and different states in India has their distinctive handloom and crafting techniques 


\section{Panchadhyayi- Gender, Windowhood and Female Solidarity}

to produce sari. See https://timesofindia.indiatimes.com/life-style/fashion/buzz/the-history-ofsari-the-nine-yard-wonder/articleshow/70277974.cms?TOI_browsernotification=true

${ }^{10}$ See endnote iii

11 The term seva refers to benevolence, reciprocity and altruistic attitude manifested through attending to the concerns and care of the elderly as enmeshed in the discourse of Hinduism illuminated in the work of Sarah Lamb, White Saris and Sweet Mangoes (2000).

12 The term sansaar refers to the private sphere of family and the everyday affairs associated with the maintenance of family and household.

\section{References}

Adams, R. G. (1985). People would talk: Normative barriers to cross-sex friendships for elderly women. The Gerontologist, 25(6), 605-611.

Adams, R. G. (1986). Emotional closeness and physical distance between friends: Implications for elderly women living in age-segregated and age-integrated settings. The International Journal of Aging and Human Development, 22(1), 55-76.

Adams, R. G. (1987). Patterns of network change: A longitudinal study of friendships of elderly women. The Gerontologist, 27(2), 222-227.

Allan, G. (2008). Flexibility, Friendship, and Family. Personal Relationships 15 (1), 1-16.

Bagchi, J. (1993). Socialising the girl child in colonial Bengal. Economic and Political Weekly, 2214-2219.

Bagchi, K. (1996). Elderly Females in India; Their Status and Suffering.

New Delhi: Society for Gerontological Research and Help Age.

Bauman, Z. (2003). On the difficulty of loving thy neighbour. In Liquid love:

On the frailty of human bonds. Cambridge: Polity Press.

Beeson, D. (1975). Women in Studies of Aging: A critique and suggestion.

Social Problems 23(1), 52-59.

Bengtson, V.L. (2001). Beyond the Nuclear Family: The Increasing Importance of Multigenerational Bonds: The Burgess Award Lecture. Journal of Marriage and Family 63(1), 1-16.

Bird, S.R. (1996). Welcome to the Men's Club: Homosociality and the Maintenance of Hegemonic Masculinity. Gender \& Society 10(2), 120-132.

Blau, Z.S. (1961). Structural Constraints on Friendships in Old Age. American Sociological Review, 429-439. 
Blieszner, R., Ogletree, A. M., and Adams, R. G. (2019). Friendship in later life: A research agenda. Innovation in Aging, 3(1), igz005.

Davidson, K. (2004). "Why Can't a Man Be More like a Woman?": Marital Status and Social Networking of Older Men. The Journal of Men's Studies, 13(1), 25-43.

Fox, M., Gibbs, M., and Auerbach, D. (1985). Age and Gender Dimensions of Friendship. Psychology of Women Quarterly 9(4), 489-502.

Jerrome, D. (1981). The Significance of Friendship for Women in Later Life. Ageing \& Society 1(2), 175-197.

Jerrome, D. (1990). Frailty and friendship. Journal of Cross-Cultural Gerontology 5(1), 51-64.

Lamb, S. (2000). White saris and sweet mangoes: Aging, Gender, and Body in North India. California: University of California Press.

Lamb, S. (2009). Aging and the Indian diaspora: Cosmopolitan Families in India and Abroad. Indiana: Indiana University Press.

Mannell, R.C., Dupuis, S., and Birren, J.E., (1996). Network Analysis. In Encyclopedia of Gerontology, 244-251. San Diego, USA: Pergamaon Press.

Miller, L., Rozin, P., and Fiske, A.P. (1998). Food sharing and feeding another person suggest intimacy; two studies of American college students. European Journal of Social Psychology 28(3), 423-436.

Mullins, L. C., and Dugan, E. (1990). The influence of depression, and family and friendship relations, on residents' loneliness in congregate housing. The Gerontologist, 30(3), 377-384.

Pahl, R., and Pevalin, D.J. (2005). Between family and friends: a longitudinal study of friendship choice. The British Journal of Sociology, 56(3), 433-450.

Ritzer, G., and Stepnisky, J. (2017). Modern Sociological Theory. London: Sage Publications.

Stevens, N. (2001). Combating loneliness: A friendship enrichment programme for older women. Ageing \& Society 21(2), 183-202.

Streib, G.F. (1970). Old Age and the family: Facts and Forecasts. American Behavioral Scientist 14(1), 25-39.

Victor, C. (2004). Family and social Networks. In The Social Context of Ageing: A textbook of Gerontology, 187-228. Milton Park, Abingdon: Routledge. 
50 Panchadhyayi- Gender, Windowhood and Female Solidarity

Sayendri Panchadhyayi. PhD Research Scholar. Dep. of Sociology. Presidency University

Contact Address: 86/1, College Street. Kolkata- 700073 West Bengal, India. sayendri@gmail.com 